ASSIS, Fábio José Silva de; VIEIRA, José Ribas. Do neoconstitucionalismo ao novo constitucionalismo latino-americano: um processo de luta das minorias. Revista Eletrônica Direito e Política, Programa de Pós-Graduação Stricto Sensu em Ciência Jurídica da UNIVALI, Itajaí, v.11, n.3, $3^{\circ}$ quadrimestre de 2016. Disponível em: www.univali.br/direitoepolitica - ISSN 1980-7791.

\title{
DO NEOCONSTITUCIONALISMO AO NOVO CONSTITUCIONALISMO LATINO-AMERICANO: UM PROCESSO DE LUTA DAS MINORIAS
}

\author{
OFF THE NEOCONSTITUTIONALISM TO THE NEW LATIN AMERICAN \\ CONSTITUTIONALISM: A PROCESS OF FIGHT OF MINORITIES
}

Fábio José Silva de Assis ${ }^{1}$

José Ribas Vieira²

\begin{abstract}
SUMÁRIO: Introdução; $1 . \quad 0$ Neoconstitucionalismo; 2. O Novo Constitucionalismo Latino-americano e o Estado Plurinacional; 3. O processo de luta das minorias latino-americanas; Considerações finais; Referências das fontes citadas.
\end{abstract}

\section{RESUMO}

Este artigo objetiva analisar a recente trajetória político-institucional do Constitucionalismo, desde o neoconstitucionalismo até o novo Constitucionalismo Latino-Americano. O estudo empreendido aponta para o fato de que embora o neoconstitucionalismo seja responsável por uma série de avanços sociais, é fácil constatar suas insuficiências institucionais. Em conseqüência a isso, surgiram diversos movimentos populares clamando pelo reconhecimento de direitos e por participação política. É nesse universo que prospera o denominado novo constitucionalismo, que, materializado na forma de Estado Plurinacional, reconheceu e garantiu direitos de parcelas minoritárias da sociedade. Utilizandose dos métodos dedutivo e histórico como forma de abordagem do tema e partindo de um estudo bibliográfico, descritivo e jurisdicional, esta pesquisa pretende compreender as influências e as limitações do neoconstitucionalismo para o adensamento do novo constitucionalismo latino-americano nessas sociedades. O presente estudo nos permitiu concluir, todavia, que muitas delas ainda possuem traços das suas Constituições anteriores, com características autoritárias, mas que de forma gradual vem conseguindo grandes conquistas sociais.

\footnotetext{
${ }^{1}$ Mestre em Teorias Jurídicas Contemporâneas pelo Programa de Pós-Graduação em Direito (PPGD) da Universidade Federal do Rio de Janeiro (UFRJ). E-mail: fabio1000assis@hotmail.com

2 Professor titular de Teoria do Direito e Direito Constitucional da "Universidade Federal Fluminense" (UFF). Professor Associado da "Pontifícia Universidade Católica do Rio de Janeiro" (PUC-RIO). Professor Titular de Teoria do Estado da "Universidade Federal do Rio de Janeiro" (UFRJ). Doutor em Direito pela Universidade Federal do Rio de Janeiro. Pós-doutor pela Universite de Montpellier I. Mestre em Direito pela Universidade Federal do Rio de Janeiro. Mestre em Ciência Política pelo Ohio University. E-mail: jribas@ufrj.br
} 
ASSIS, Fábio José Silva de; VIEIRA, José Ribas. Do neoconstitucionalismo ao novo constitucionalismo latino-americano: um processo de luta das minorias. Revista Eletrônica Direito e Política, Programa de Pós-Graduação Stricto Sensu em Ciência Jurídica da UNIVALI, Itajaí, v.11, n.3, $3^{\circ}$ quadrimestre de 2016. Disponível em: www.univali.br/direitoepolitica - ISSN 1980-7791.

Palavras-chave: Neoconstitucionalismo; Novo Constitucionalismo Latinoamericano; Direitos das minorias.

Abstract: This article aims to analyze the recent political and institutional trajectory of Constitutionalism, going from the Neoconstitutionalism until the New Latin American Constitutionalism. This study shows the fact that although the Neoconstitutionalism is responsible for a number of social advances, it is easy to see its institutional shortcomings. Because of this, there were several popular movements calling for recognition of rights and political participation. It is in this universe that emerge the so called new constitutionalism, which materialized in the form of the Plurinational State, recognized and guaranteed rights of minority segments of society. Using the deductive and historical methods as a way of approach to the subject and starting from a bibliographic, descriptive and jurisdictional study, this research aims to understand the influences and limits of neoconstitutionalism to offer density to the new Latin American constitutionalism in these societies. This study allowed us to conclude, however, that many of them still have traces of their previous Constitutions, with authoritarian characteristics, but gradually has managed great social achievements.

Keywords: Neoconstitutionalism; New Constitutionalism Latin American; Minority Rights.

\section{INTRODUÇÃO}

A maioria dos ordenamentos jurídicos ocidentais tem como seu principal elemento a Constituição. O constitucionalismo moderno surgiu no fim do século XVIII, ganhando força com as revoluções inglesa, francesa e americana. Com a derrubada das monarquias, impulsionada primordialmente pela Revolução Francesa, constituíram-se os Estados independentes, que tinham como característica a valorização do elemento formalista que os constituía, de forma que as Constituições passaram, cada vez mais, a ocupar posições de destaque. Soma-se a esse aspecto o caráter de limitação de poderes e os fundamentos liberalistas que emergiam no período em questão.

Dito isso, podemos definir a noção de constitucionalismo como um sistema político que se fundamenta no regime constitucional, de forma que as constituições se tornam o centro do ordenamento jurídico estatal. No entanto, na Europa pós Segunda Guerra Mundial, as antigas noções formalistas e positivistas 
ASSIS, Fábio José Silva de; VIEIRA, José Ribas. Do neoconstitucionalismo ao novo constitucionalismo latino-americano: um processo de luta das minorias. Revista Eletrônica Direito e Política, Programa de Pós-Graduação Stricto Sensu em Ciência Jurídica da UNIVALI, Itajaí, v.11, n.3, $3^{\circ}$ quadrimestre de 2016. Disponível em: www.univali.br/direitoepolitica - ISSN 1980-7791.

extremadas começaram a sofrer significativo abalo: a idéia de um ordenamento jurídico desprovido de valores éticos e morais já não era mais aceita. Conforme elucida Barroso ${ }^{3}$, a superação histórica do jusnaturalismo e o fracasso político do positivismo abriram caminho para um conjunto amplo e ainda inacabado de reflexões acerca do Direito, sua função social e sua interpretação.

Dessa forma, o sistema anterior foi ganhando novos contornos, surgindo o que se denomina de neoconstitucionalismo, com a introdução de novos valores constitucionais, como os direitos fundamentais e a dignidade da pessoa humana. Os direitos humanos foram concebidos como resposta a esse período de guerra e desrespeito à condição humana, e seu desenvolvimento seguiu nos períodos posteriores, atrelando-se com o próprio desenvolvimento do constitucionalismo moderno.

Nesse neoconstitucionalismo se busca explicar o direito tendo como paradigma o Estado Democrático, visto como um meio de garantir direitos fundamentais para todos, rompendo com a anterior visão de uma constituição de direitos meramente formal. Os direitos fundamentais, em seu caráter axiológico, são verdadeiros pressupostos do neoconstitucionalismo, assim como a limitação de poderes, a crítica ao absolutismo e o protagonismo da Constituição o são para o constitucionalismo clássico. O neoconstitucionalismo tem como base uma teorização jurídica voltada para uma acepção constitucional do Estado Democrático de Direito, priorizadora dos direitos fundamentais. Em síntese, poderíamos dizer que:

[...] o neoconstitucionalismo ou novo direito constitucional, na acepção aqui desenvolvida, identifica um conjunto amplo de transformações ocorridas no Estado e no direito constitucional, em meio às quais podem ser assinalados, (i) como marco histórico, a formação do Estado constitucional de direito, cuja consolidação se deu ao longo das décadas finais do século XX; (ii) como marco filosófico, o pós-

3 BARROSO, Luís Roberto. Interpretação e Aplicação da Constituição. 6 ed. São Paulo: Saraiva, 2008, p.27. 
ASSIS, Fábio José Silva de; VIEIRA, José Ribas. Do neoconstitucionalismo ao novo constitucionalismo latino-americano: um processo de luta das minorias. Revista Eletrônica Direito e Política, Programa de Pós-Graduação Stricto Sensu em Ciência Jurídica da UNIVALI, Itajaí, v.11, n.3, $3^{\circ}$ quadrimestre de 2016. Disponível em: www.univali.br/direitoepolitica - ISSN 1980-7791.

positivismo, com a centralidade dos direitos fundamentais e a reaproximação entre Direito e ética $[\ldots]^{4}$.

Esse debate do neoconstitucionalismo, já consolidado em diversos ordenamentos jurídicos, vem permitindo o adensamento do que a doutrina vem chamando de "novo constitucionalismo latino-americano". Esse último busca positivar direitos pluralistas e democráticos, com foco no diálogo social, como forma de garantir uma ordem pautada na igualdade, levando em consideração uma sociedade plural e multicultural e em como as decisões judiciais refletem nessa sociedade.

O novo constitucionalismo latino-americano surgiu principalmente dentre as comunidades indígenas, que a partir de um processo de lutas sociais por reconhecimento e por igualdade de direitos, passou a exigir uma Constituição que respeitasse a multiculturalidade e as características de todos os povos, de forma a criar um legítimo Estado que se pretende Democrático de Direito, por meio do protagonismo social.

Alguns países vizinhos ao Brasil, como Bolívia e Equador, tem reformado suas constituições, incluindo a participação popular na tomada de decisões, integrando todas as camadas da população e trazendo uma maior preocupação com a vigência dos direitos fundamentais.

Embora possamos afirmar que o neoconstitucionalismo foi essencial para o surgimento do novo constitucionalismo latino-americano, Roberto Viciano Pastor e Rubén Martínez Dalmau defendem que o neoconstitucionalismo é uma corrente doutrinária, produto de anos de teorização acadêmica, enquanto que o novo constitucionalismo é um fenômeno surgido fora da Academia, sendo um produto mais das reivindicações e movimentos sociais do que dos professores de direito constitucional $^{5}$.

\footnotetext{
4 BARROSO, Luis Roberto. Neoconstitucionalismo e constitucionalização do Direito: 0 triunfo tardio do Direito Constitucional no Brasil. Revista de Direito Administrativo da FGV, Rio de Janeiro, $2005 . \quad$ Disponível em: <http://bibliotecadigital.fgv.br/ojs/index.php/rda/article/view/43618/44695>. Acesso em: 05.set. 2015.

5 MARTINEZ DALMAU, Rubén; VICIANO PASTOR, Roberto. ¿Se pude hablar de un nuevo constitucionalismo latinoamericano como corriente doctrinal sistematizada? Trabalho
} 
ASSIS, Fábio José Silva de; VIEIRA, José Ribas. Do neoconstitucionalismo ao novo constitucionalismo latino-americano: um processo de luta das minorias. Revista Eletrônica Direito e Política, Programa de Pós-Graduação Stricto Sensu em Ciência Jurídica da UNIVALI, Itajaí, v.11, n.3, $3^{\circ}$ quadrimestre de 2016. Disponível em: www.univali.br/direitoepolitica - ISSN 1980-7791.

Como veremos nesse artigo, diferente do neoconstitucionalismo, a preocupação do novo constitucionalismo não é unicamente quanto a dimensão jurídica da Constituição, mas sim, em primeiro lugar, com a sua legitimidade democrática, trazendo um constitucionalismo que pode romper com o que se considera dado e imutável e que pode avançar pelo caminho da justiça social, da igualdade e do bem estar dos cidadãos ${ }^{6}$.

\section{O NEOCONSTITUCIONALISMO}

Antes de analisarmos o novo constitucionalismo latino-americano, é importante estudarmos o neoconstitucionalismo, tendo em vista sua importância para essa transição constitucional. Não há uma definição consolidada do que vem a ser o neoconstitucionalismo. O prefixo "neo" significa novo, com o intuito de trazer a idéia de um constitucionalismo que rompe os paradigmas anteriores e que tenha uma maior preocupação com os princípios, em detrimento das regras e do caráter formalista.

O termo neoconstitucionalismo foi inicialmente utilizado por Suzanna Pozzolo, em 1993, para denominar um certo modo antijuspositivista de se aproximar do direito ${ }^{7}$.

No entanto, alguns outros autores defendem que tal termo designa um preceito do pós-positivismo e outros o intitulam "novo paradigma", como Gloria Patrícia Lopero, que afirma que na teoria atual "parece consolidar-se o uso da expressão

apresentado no Congresso Mundial de Direito constitucional, 2010. Disponível em: <http://www.juridicas.unam.mx/wccl/ponencias/13/245.pdf>. Acesso em: 10.jan.2015.

6 MARTINEZ DALMAU, Rubén; VICIANO PASTOR, Roberto. ¿Se pude hablar de un nuevo constitucionalismo latinoamericano como corriente doctrinal sistematizada? Trabalho apresentado no Congresso Mundial de Direito constitucional, 2010. Disponível em: <http://www.juridicas.unam.mx/wccl/ponencias/13/245.pdf>. Acesso em: 10.jan.2015.

7 DUARTE, Écio Oto Ramos; POZZOLO, Susanna. Neoconstitucionalismo e positivismo jurídico: as faces da teoria do Direito em tempos de interpretação moral da Constituição. São Paulo: Landy, 2006, p.77. 
ASSIS, Fábio José Silva de; VIEIRA, José Ribas. Do neoconstitucionalismo ao novo constitucionalismo latino-americano: um processo de luta das minorias. Revista Eletrônica Direito e Política, Programa de Pós-Graduação Stricto Sensu em Ciência Jurídica da UNIVALI, Itajaí, v.11, n.3, $3^{\circ}$ quadrimestre de 2016. Disponível em: www.univali.br/direitoepolitica - ISSN 1980-7791.

neoconstitucionalismo para designar um conjunto de transformações operadas na prática e na compreensão dos ordenamentos jurídicos contemporâneos" ${ }^{\prime 8}$.

É possível entender o neoconstitucionalismo como um novo paradigma, padrão, do direito, já que ele defende uma superação no debate entre positivistas e jusnaturalistas, através de uma nova teoria para o direito, tomando como ponto central a Constituição. O direito deixa de ser o que ditam as normas, para ser um direito em que os princípios ditam o que se pode fazer. Esse pensamento difere do formalista, pois consegue alcançar as transformações práticas dentro do sistema jurídico, e afasta-se das teses jusnaturalistas, pois não se exterioriza para fora do sistema, nem defende valores universais.

Em que pese o fato do conceito ainda estar longe de ser unívoco, é possível traçarmos algumas de suas características, de acordo com o que vem delineando e construindo a doutrina. Luis Roberto Barroso traz como principais características a força normativa dada à Constituição e a criação de novas categorias de hermenêutica:

Sobreleva notar, de início, que o ambiente fértil do pós positivismo, tendo como principais características paradigmáticas, no plano teórico, a força normativa dada à Constituição, a expansão da função jurisdicional constitucional e a elaboração das diferentes categorias da nova hermenêutica constitucional (viragem lingüística), serviu de base e/ou alicerce para o desenvolvimento do neoconstitucionalismo ${ }^{9}$.

Como já explicitamos, a doutrina remonta a origem do neoconstitucionalismo ao período Pós Segunda Guerra, assim como a primazia aos direitos humanos, com as consequentes alterações nas Constituições Europeias e Americanas,

${ }^{8}$ LOPERO, Gloria. La aplicación del derecho es los sistemas jurídicos constitucionalizados. Revista Cuadernos de Investigación, Medellin. Disponível em <http://publicaciones.eafit.edu.co/index.php/cuadernos-investigacion/article/view/1325/1196>. Acesso em 20.out.2015.

9 BARROSO, Luis Roberto. Neoconstitucionalismo e constitucionalização do Direito: 0 triunfo tardio do Direito Constitucional no Brasil. Revista de Direito Administrativo da FGV, Rio de Janeiro, $2005 . \quad$ Disponível em: <http://bibliotecadigital.fgv.br/ojs/index.php/rda/article/view/43618/44695>. Acesso em: 05.set. 2015. 
ASSIS, Fábio José Silva de; VIEIRA, José Ribas. Do neoconstitucionalismo ao novo constitucionalismo latino-americano: um processo de luta das minorias. Revista Eletrônica Direito e Política, Programa de Pós-Graduação Stricto Sensu em Ciência Jurídica da UNIVALI, Itajaí, v.11, n.3, $3^{\circ}$ quadrimestre de 2016. Disponível em: www.univali.br/direitoepolitica - ISSN 1980-7791.

institucionalizando um sistema de garantias, supremacia e controle, através do controle de constitucionalidade, por exemplo, permeado pela inclusão de direitos individuais, fundamentais, nunca antes visto ${ }^{10}$.

Por esse motivo que o neoconstitucionalismo é visto como uma ruptura ao constitucionalismo até então vigente e ao positivismo legalista, trazendo uma luta diferente da que se preocupava o constitucionalismo liberal, um novo parâmetro, concepção essa que para os fins desse trabalho é a mais adequada. Nesse sentido, leciona Lênio Streck:

Isto é o neoconstitucionalismo: uma técnica ou engenharia do poder que procura dar resposta a movimentos históricos de natureza diversa daqueles que originaram 0 constitucionalismo liberal, por assim dizer (ou primeiro constitucionalismo). Por isso o neoconstitucionalismo é paradigmático; por isso ele é ruptural ${ }^{11}$.

Elucidando bem a questão, Barroso afirma que o neoconstitucionalismo é identificado por meio de três marcos: histórico, teórico e filosófico. O primeiro consistiria no constitucionalismo do pós-guerra, especialmente na Alemanha e na Itália, e no Brasil na CRFB/88 com o processo de redemocratização do país, oriundo do período autoritário anterior, protagonizado pela imposição do Poder Executivo aos demais poderes, além das diversas violações aos direitos fundamentais institucionalizadas pelos Atos Institucionais, marcos esses responsáveis por construir e fortalecer o neoconstitucionalismo.

Prova disso é o viés analítico da nossa Constituição, que buscou abarcar diversos assuntos considerados como fundamentais ao povo, tornando-se, portanto, muito extensa e pragmática.

\footnotetext{
10 VALE, Andre Rufino do. Aspectos do Neoconstitucionalismo. Revista Brasileira de Direito Constitucional, São Paulo, 2007. Disponível em <http://www.esdc.com.br/RBDC/RBDC09/RBDC-09-067-Andre_Rufino_do_Vale.pdf>. Acesso em: 11.jan.2015.

11 STRECK, Lênio Luiz. Hermenêutica, Neoconstitucionalismo e "o problema da discricionariedade dos juízes". Revista Eletrônica do Curso de Direito da OPET, Curitiba, 2009. Disponível em <http://www.animaopet.com.br/primeira_edicao/artigo_Lenio_Luiz_Streck_hermeneutica.pdf>. Acesso em 11.jan.2015.
} 
ASSIS, Fábio José Silva de; VIEIRA, José Ribas. Do neoconstitucionalismo ao novo constitucionalismo latino-americano: um processo de luta das minorias. Revista Eletrônica Direito e Política, Programa de Pós-Graduação Stricto Sensu em Ciência Jurídica da UNIVALI, Itajaí, v.11, n.3, $3^{\circ}$ quadrimestre de 2016. Disponível em: www.univali.br/direitoepolitica - ISSN 1980-7791.

Já no plano teórico são trazidos três marcos, os quais subverteram o conhecimento convencional quanto à aplicação do direito constitucional: a) o reconhecimento de força normativa à Constituição; b) a expansão da jurisdição constitucional; e c) o desenvolvimento de uma nova dogmática da interpretação constitucional ${ }^{12}$.

Por fim, como marco filosófico é apontado o pós-positivismo, responsável pela superação do jusnaturalismo e do positivismo, ao agregar valores ao direito positivado, como já pontuamos.

Há ainda outra face do neoconstitucionalismo, observada através de sua aplicação concreta, afeta ao estudo da teoria da interpretação e prática jurídicas, elevando a prerrogativa de dizer o direito constitucional - no Brasil, atribuição exercida por todos os juízos, em função do controle difuso, interpretação e ponderação principiológica, fundamentações decisionais em dispositivos constitucionais, e outros objetivos almejados pela Constituição Federal- ao grande saber da jurisprudência.

É crescente o percentual de decisões que utiliza ponderação e hermenêutica, de forma que a interpretação do direito se concretiza no final do século $X X$ com a sedimentação da interpretação constitucional, que tem como base a Constituição Federal, elevando os princípios constitucionais como fonte primária do direito. Nesse ponto, vale citar as ideias de Suzana Pozzolo que, elencando traços do neoconstitucionalismo, afirma:

Entre os muitos traços que podem caracterizar 0 neoconstitucionalismo, podemos evidenciar os seguintes: a) a adoção de uma noção específica de Constituição que foi denominada "modelo prescritivo de Constituição como norma"; b) a defesa da tese segundo a qual o direito é composto (também) de princípios; c) a adoção da técnica interpretativa denominada "ponderação" ou "balanceamento"; d) a consignação de tarefas da

\footnotetext{
${ }^{12}$ BARROSO, Luis Roberto. Neoconstitucionalismo e constitucionalização do Direito: 0 triunfo tardio do Direito Constitucional no Brasil. Revista de Direito Administrativo da FGV, Rio de Janeiro, $2005 . \quad$ Disponível em: <http://bibliotecadigital.fgv.br/ojs/index.php/rda/article/view/43618/44695>. Acesso em: 05.set. 2015.
} 
ASSIS, Fábio José Silva de; VIEIRA, José Ribas. Do neoconstitucionalismo ao novo constitucionalismo latino-americano: um processo de luta das minorias. Revista Eletrônica Direito e Política, Programa de Pós-Graduação Stricto Sensu em Ciência Jurídica da UNIVALI, Itajaí, v.11, n.3, $3^{\circ}$ quadrimestre de 2016. Disponível em: www.univali.br/direitoepolitica - ISSN 1980-7791.

integração à jurisprudência e de tarefas pragmáticas à Teoria do Direito ${ }^{13}$. (negritou-se)

Esse protagonismo da Constituição não se restringe à sua aplicação judicial, afetando também toda a noção de governo e a atividade legiferante. Esta passa a ter como base e limite os ditames constitucionais que, caso não respeitados, levarão o controle de constitucionalidade a incidir sobre o ato normativo e sua incorreção, atividade desempenhada pelo Judiciário; e as opções políticas e políticas públicas efetivadas pelo Executivo devem almejar os direcionamentos constitucionais, sob pena de, sobre elas, também incidir o controle por parte do Judiciário.

Com isso, podemos concluir que o neoconstitucionalismo reafirma a idéia de supremacia da Constituição, orientando o funcionamento do Estado Democrático de Direito; privilegia a supremacia dos princípios dentro do ordenamento jurídico; e prima pela aplicação dos direitos e garantias fundamentais, de forma que a jurisdição constitucional só tem sentido completo com a observação substancial desses direitos, que através do processo interpretativo atingem sua máxima concretização, abandonando a ideia meramente formal de direitos, oriunda do constitucionalismo liberal.

Essa concepção do neoconstitucionalismo, como ponto de partida para as discussões acerca do novo constitucionalismo latino americano, como uma fase de evolução doutrinária, caracterizada justamente pela introdução de normas materiais e substantivas que condicionam a atuação do Estado no cumprimento de certos fins e objetivos, e que apareceu a partir dos acontecimentos da Segunda Guerra é essencial para os pontos seguintes, e defendida por diversos autores, como já exemplificado.

\footnotetext{
13 DUARTE, Écio Oto Ramos; POZZOLO, Susanna. Neoconstitucionalismo e positivismo jurídico: as faces da teoria do Direito em tempos de interpretação moral da Constituição, p.77.
} 
ASSIS, Fábio José Silva de; VIEIRA, José Ribas. Do neoconstitucionalismo ao novo constitucionalismo latino-americano: um processo de luta das minorias. Revista Eletrônica Direito e Política, Programa de Pós-Graduação Stricto Sensu em Ciência Jurídica da UNIVALI, Itajaí, v.11, n.3, $3^{\circ}$ quadrimestre de 2016. Disponível em: www.univali.br/direitoepolitica - ISSN 1980-7791.

\section{O NOVO CONSTITUCIONALISMO LATINO-AMERICANO E O ESTADO PLURINACIONAL}

Diferente do neoconstitucionalismo, que tem origens européias, o novo constitucionalismo se originou nos Estados Latino-Americanos. Nesses países, após reivindicações de parcelas da sociedade historicamente excluídas, principalmente no que tange às populações indígenas, suas Constituições vêm sofrendo modificações, garantindo direitos que durante séculos the foram negados. Podem ser usados como principais exemplos a promulgação das Constituições do Equador e da Bolívia, que trazem uma ruptura drástica com o constitucionalismo moderno.

Nesse novo constitucionalismo são consideradas as manifestações do povo, não só por representação, mas principalmente por meio direto, inclusive no que tange a sua composição plural. Com isso, são incorporadas as reivindicações de parcelas sociais que eram excluídas do processo decisório. Essa mudança radical daria origem a um novo Estado: o Estado Plurinacional, que tem como característica a implementação de uma democracia consensual e participativa.

Graças ao novo constitucionalismo latino-americano, a nossa América finalmente anuncia algo de novo, democrático e tolerante, capaz de romper com a intolerância unificadora e violenta ${ }^{14}$.

Com isso, esse novo constitucionalismo traz novos atores sociais, realidades plurais e o respeito a culturas minoritárias, principalmente dos povos indígenas.

Viciano Pastor e Martinez Dalmau, dois dos principais autores sobre o tema, trazem algumas características sobre o novo constitucionalismo latinoamericano, que nos permite ter uma compreensão sistematizada.

São elas: a) substituição da continuidade constitucional pela ruptura com o sistema anterior, com fortalecimento, no âmbito simbólico, da dimensão política da Constituição; b) capacidade inovadora dos textos, buscando a integração

\footnotetext{
14 MAGALHÃES, José Luiz Quadros de. Estado plurinacional e direito internacional. Curitiba:
} Juruá, 2012, p.31. 
ASSIS, Fábio José Silva de; VIEIRA, José Ribas. Do neoconstitucionalismo ao novo constitucionalismo latino-americano: um processo de luta das minorias. Revista Eletrônica Direito e Política, Programa de Pós-Graduação Stricto Sensu em Ciência Jurídica da UNIVALI, Itajaí, v.11, n.3, $3^{\circ}$ quadrimestre de 2016. Disponível em: www.univali.br/direitoepolitica - ISSN 1980-7791.

nacional e uma nova institucionalidade; c) fundamentação baseada em princípios, em detrimento de regras; d) extensão do próprio texto constitucional, em decorrência tanto do passado constitucional, quanto da complexidade dos temas, mas veiculada em linguagem acessível; e) proibição de que os poderes constituídos disponham da capacidade de reforma constitucional por si mesmos e, pois, um maior grau de rigidez, dependente de novo processo constituinte; f) busca de instrumentos que recomponham a relação entre soberania e governo, com a democracia participativa como complemento do sistema representativo; g) uma extensiva carta de direitos, com incorporação de tratados internacionais e integração de setores marginalizados; h) a passagem de um predomínio do controle difuso de constitucionalismo pelo controle concentrado, incluindo-se fórmulas mistas; i) um novo modelo de "constituições econômicas", simultâneo a um forte compromisso de integração latino-americana de cunho não meramente econômico ${ }^{15}$.

Wolkmer divide o surgimento e desenvolvimento do novo constitucionalismo em três ciclos, estando Brasil e Colômbia no primeiro ciclo; Venezuela no segundo; e Equador e Bolívia no terceiro. Para o autor, o primeiro ciclo teria sido social e descentralizador das Constituições.

O segundo ciclo encaminhou-se para um constitucionalismo participativo e pluralista, em que a representação nuclear desse processo constitucional passa pela Constituição Venezuelana de 1999.

O terceiro ciclo é representado pelas recentes e vanguardistas Constituições do Equador (2008) e da Bolívia (2009). Tais textos políticos expressariam um constitucionalismo plurinacional comunitário, identificado com outro paradigma não universal e único de Estado de Direito, coexistente com experiências de sociedades interculturais (indígenas, comunais, urbanas e camponesas) e com práticas de pluralismo igualitário jurisdicional (convivência de instâncias legais

\footnotetext{
15 BALDI, César Augusto. Novo constitucionalismo latino-americano. Revista Estado de Direito, Porto Alegre, 2011. Disponível em <http://files.campus.edublogs.org/blogs.udla.edu.ec/dist/0/59/files/2011/11/novoconstitucionali smolatinoamericano-portugues-1z5jvul.pdf>. Acesso em: 15.jan.2015.
} 
ASSIS, Fábio José Silva de; VIEIRA, José Ribas. Do neoconstitucionalismo ao novo constitucionalismo latino-americano: um processo de luta das minorias. Revista Eletrônica Direito e Política, Programa de Pós-Graduação Stricto Sensu em Ciência Jurídica da UNIVALI, Itajaí, v.11, n.3, $3^{\circ}$ quadrimestre de 2016. Disponível em: www.univali.br/direitoepolitica - ISSN 1980-7791.

diversas em igual hierarquia: jurisdição ordinária estatal e jurisdição indígena/camponesa).

Por esse novo constitucionalismo propor uma diversidade de culturas minoritárias e a força dos povos indígenas, Wolkmer o denominou de Constitucionalismo Pluralista Intercultural, representando uma nova realidade constitucional latinoamericana. Em suas palavras:

Parece evidente que as mudanças políticas e os novos processos sociais de luta nos Estados latino-americanos engendraram não só novas constituições que materializaram novos atores sociais, realidades plurais e práticas desafiadoras, mas, igualmente, propõem, diante da diversidade de culturas minoritárias e da força inconteste dos povos indígenas do Continente, um novo paradigma de constitucionalismo, 0 que poderia denominar-se Constitucionalismo Pluralista Intercultural (compreendendo, aqui, as expressões que já vêm sendo utilizadas: constitucionalismo andino ou indígena).

Enfim, nesse processo, é essencial que a Teoria do Direito e do Estado Constitucional tome em consideração o exame do Pluralismo Jurídico, para compreender a nova realidade constitucional latino-americana ${ }^{16}$.

Já Boaventura de Sousa Santos explica que da plurinacionalidade derivam a interculturalidade e a pós-colonialidade ${ }^{17}$, características essas bem marcantes no novo constitucionalismo. Para o autor, essa plurinacionalidade modifica o Estado moderno ao congregar diferentes conceitos de nação em um mesmo Estado, se inserindo a idéia de que as forças plurinacionais "implicam, obviamente, em refundar o Estado moderno; porque o mesmo é um Estado que

16 WOLKMER, Antonio Carlos. Pluralismo e Constitucionalismo na Tradição Jurídico Brasileira e Latino-Americana. Conferência: Pluralismo e constitucionalismo no Brasil, proferida no II Congresso de Estudos Jurídicos do Centro Acadêmico Cromwell de Carvalho e Escola Superior de Advocacia do Piauí, realizado em 2011, em Teresina - Piauí - Brasil, p. 10-12.

17 A interculturalidade pressupõe que o povo tenha uma cultura comum, compartilhada. Para ela, as sociedades são distintas, tendo cada uma delas sua cultura comum que as distingue das demais e que é compartilhada entre seus integrantes. Quanto as correntes pós-colonialistas, essas defendem que o colonialismo não se extingue com a independência. Boaventura Santos utiliza, como exemplo, o Brasil, em que mesmo após 184 anos da independência, ainda era um país racista, que precisava de ações afirmativas nesse sentido, como um sistema de cotas. 
ASSIS, Fábio José Silva de; VIEIRA, José Ribas. Do neoconstitucionalismo ao novo constitucionalismo latino-americano: um processo de luta das minorias. Revista Eletrônica Direito e Política, Programa de Pós-Graduação Stricto Sensu em Ciência Jurídica da UNIVALI, Itajaí, v.11, n.3, $3^{\circ}$ quadrimestre de 2016. Disponível em: www.univali.br/direitoepolitica - ISSN 1980-7791.

tem uma única nação, e neste momento tem que combinar diferentes conceitos de nação dentro de um só Estado"18.

Dessa forma, em um Estado plurinacional, o Estado e a Constituição representam uma única nação, um único direito, sem interesses ou culturas divergentes. Seu paradigma é exatamente o novo constitucionalismo latino-americano, que se origina em países que tem um histórico de dominação, em que apenas uma pequena parcela da população dispõe do direito a uma representação efetiva. 0 Estado Plurinacional traz, então, a idéia de uma democracia consensual, deixando de lado a centralização do Estado Nacional e a democracia representativa ${ }^{19}$, que acabavam por excluir as minorias, justamente por serem numericamente inferiores.

\section{O PROCESSO DE LUTA DAS MINORIAS LATINO-AMERICANAS}

O processo de conquista da América Latina foi marcado pelo genocídio dos povos nativos e da sua conseqüente subjugação e exploração, o que representou apenas o início do desrespeito e da negação da cultura desses povos, por meio da imposição de uma identidade nacional criada à imagem da europeia.

Dentro desse contexto de intolerância, que foi instaurado nesses países o Estado Moderno, como uma ferramenta de manutenção dessa estrutura de poder dominante, excluindo negros e índios de qualquer idéia de nacionalidade. $\mathrm{Na}$ América Latina, quando formados os Estados nacionais, não era interessante para as classes dominantes que negros e índios se sentissem possuidores de direitos ou de nacionalidade.

\footnotetext{
18 SANTOS, Boaventura de Sousa. La reinvención del Estado y el Estado plurinacional, OSAL, Buenos Aires, $2007 . \quad$ Disponível em <http://bibliotecavirtual.clacso.org.ar/ar/libros/osal/osal22/D22SousaSantos.pdf>. Acesso em: 21.dez.14.

${ }^{19}$ A título de esclarecimento, Boaventura de Sousa Santos nos traz em sua obra a diferenciação da democracia representativa para a democracia participativa: "na democracia representativa elegemos os que tomam as decisões políticas; na democracia participativa, os cidadãos decidem, tomam as decisões" [SANTOS, Boaventura de Sousa. Renovar a teoria crítica e reinventar a emancipação social. São Paulo: Boitempo, 2007, p.92].
} 
ASSIS, Fábio José Silva de; VIEIRA, José Ribas. Do neoconstitucionalismo ao novo constitucionalismo latino-americano: um processo de luta das minorias. Revista Eletrônica Direito e Política, Programa de Pós-Graduação Stricto Sensu em Ciência Jurídica da UNIVALI, Itajaí, v.11, n.3, $3^{\circ}$ quadrimestre de 2016. Disponível em: www.univali.br/direitoepolitica - ISSN 1980-7791.

Para Magalhães, no Brasil, por exemplo, pôde se enxergar duas formas de lidar com a população indígena: ou por meio de uma total omissão, como se esses povos não existissem ou fossem apenas um depósito de pessoas que seriam integradas cedo ou tarde; ou por meio de uma política de proteção com a criação de refúgios para esses povos, desconsiderando seus territórios originais ${ }^{20}$.

Nas palavras bem elucidantes do autor:

Na América Latina os Estados nacionais se formam a partir das lutas pela independência no decorrer do século XIX. Um fator comum nestes Estados é o fato de que, quase invariavelmente, foram Estados construídos para uma parcela minoritária da população, onde não interessava para as elites econômicas e militares, que a maior parte da população se sentisse integrante, se sentisse parte de Estado. Desta forma, em proporções diferentes em toda a América, milhões de povos originários (de grupos indígenas os mais distintos) assim como milhões de imigrantes forçados africanos, foram radicalmente excluídos de qualquer idéia de nacionalidade. O direito não era para estas maiorias, a nacionalidade não era para estas pessoas. Não interessava às elites que indígenas e africanos se sentissem nacionais.

De forma diferente da Europa onde foram construídos estados nacionais para todos que se enquadrassem ao comportamento religioso imposto pelos estados, na América não se esperava que os indígenas e negros se comportassem como iguais, era melhor que permanecessem à margem, ou mesmo, no caso dos indígenas, que não existissem: milhões foram mortos.

Neste sentido, as revoluções da Bolívia e do Equador, seus poderes constituintes democráticos, fundam um novo Estado, capaz de superar a brutalidade dos estados nacionais nas Américas: o Estado plurinacional, democrático e popular.

Nunca na América, tivemos tantos governos democráticos populares como neste surpreendente século XXI. O importante é que estes governos não são apenas democráticos representativos, mas, fortemente participativos, dialógicos.

${ }^{20}$ SANTOS, Boaventura de Sousa. Reconhecer para libertar: os caminhos do cosmopolitismo cultural. Rio de Janeiro: Civilização Brasileira, 2003, p. 79. 
ASSIS, Fábio José Silva de; VIEIRA, José Ribas. Do neoconstitucionalismo ao novo constitucionalismo latino-americano: um processo de luta das minorias. Revista Eletrônica Direito e Política, Programa de Pós-Graduação Stricto Sensu em Ciência Jurídica da UNIVALI, Itajaí, v.11, n.3, $3^{\circ}$ quadrimestre de 2016. Disponível em: www.univali.br/direitoepolitica - ISSN 1980-7791.

Uma idéia nova, neste processo chama a atenção: o Estado Plurinacional das Constituições do Equador e da Bolívia ${ }^{21}$.

Desde a colonização das Américas Espanhola e Portuguesa, que hoje constituem a América Latina, que seus povos indígenas são escravizados, extintos e têm sua cultura desrespeitada, com base em um paradigma de inferioridade instalado no processo de conquista desses países. A cultura desses povos foi ignorada por seus colonizadores, que os viam com inferioridade, ignorando suas realidades e suas relações sociais.

Tal dinâmica pode ser enquadrada no que Joaquín Herrera Flores vai chamar de "circuito de reação cultural", em que cada acontecimento é percebido de forma diferenciada em sua realidade. E cada um reage em relação a esse evento conforme sua posição. $\mathrm{E}$, com isso, dentro desse circuito, durante muitos anos se estabeleceu uma relação entre dominantes e dominados. Para Herrera Flores, todo produto cultural surge numa determinada realidade, ou seja, num específico e histórico marco de relações sociais, psíquicas e naturais. Não há produtos culturais à margem do sistema de relações que constitui suas condições de existência. Não há produtos culturais em si próprios.

Todos surgem como respostas simbólicas a determinados contextos de relações. Dito isso, os produtos culturais não só estão determinados por tal contexto, mas, por sua vez, condicionam a realidade na qual se inserem ${ }^{22}$.

Nesse circuito de reação cultural, todos os atores sociais podem reagir e transformar a realidade por meio de produtos culturais, chamados pelo autor de processos emancipadores. Esses processos emancipadores são contrahegemônicos e plurais, afastando qualquer tentativa de homogeneidade e

\footnotetext{
21 MAGALHÃES, José Luiz Quadros de. O Estado Plurinacional na América Latina. Conteúdo Jurídico, Brasília-DF: 2009. Disponível em: <http://www.conteudojuridico.com.br/?colunas\&colunista=50\&ver=257>. Acesso em: 19 jan. 2015.
}

22 FLORES, Joaquin Herrera. Teoria crítica dos direitos humanos. Rio de Janeiro, Lumen Juris, 2009, p. 89. 
ASSIS, Fábio José Silva de; VIEIRA, José Ribas. Do neoconstitucionalismo ao novo constitucionalismo latino-americano: um processo de luta das minorias. Revista Eletrônica Direito e Política, Programa de Pós-Graduação Stricto Sensu em Ciência Jurídica da UNIVALI, Itajaí, v.11, n.3, $3^{\circ}$ quadrimestre de 2016. Disponível em: www.univali.br/direitoepolitica - ISSN 1980-7791.

eliminação das diferenças ${ }^{23}$, caso abordado no presente artigo quanto aos direitos das minorias, que, como veremos abaixo, passaram a exigir a efetivação de direitos em relação a sua cultura e identidade.

As Constituições anteriores desses Estados latino-americanos, criadas de acordo com um modelo europeu, tinham inseridos apenas direitos e garantias de cunho individualista, sem qualquer preocupação com a criação de direitos que integrassem os povos.

A heterogeneidade era vista com intolerância e mascarada por normas pseudoinclusivistas que apenas serviam para intensificar as diferenças. Nas palavras de Boaventura dos Santos:

As políticas públicas e as leis, porém, se propuseram durante muitos anos a cumprir essa vontade dos Estados nacionais: integrar os povos como cidadãos, sujeitos de direito, capazes de negociar juridicamente, sem reconhecer seus direitos coletivos. Nesta perspectiva o genocídio continuou, e cada tentativa de integração desses povos significou a continuação do estado de guerra imposto quando da chegada dos europeus. Os povos perdiam não só a visibilidade, mas a própria vida $[\ldots]$.

A conseqüência desta diferença é que, na América, os povos tiveram mais dificuldade de manter sua vida segundo seus usos, costumes e tradições; a própria solução de seus conflitos internos dependia das leis dos respectivos Estados nacionais. A integração, no caso latino-americano, como era proposta de forma individualizada, significava a extinção do povo ${ }^{24}$.

Tal fato levou essa parcela da população a se fragmentar e marginalizar, o que, a partir de 1950, foi alvo de lutas sociais por reconhecimento contra as forças dominantes e contra conceitos tradicionais, período pelo qual esses povos indígenas vêm conquistando gradativamente seu espaço nas searas política e legal, passando a serem vistos como novos sujeitos coletivos de direitos.

${ }^{23}$ FLORES, Joaquín Herrera El processo cultural: materiales para La creatividad humana. Sevilla, Aconchagua Libros, 2005, p. 95.

${ }^{24}$ SANTOS, Boaventura de Sousa. Reconhecer para libertar: os caminhos do cosmopolitismo cultural, p. 78-79. 
ASSIS, Fábio José Silva de; VIEIRA, José Ribas. Do neoconstitucionalismo ao novo constitucionalismo latino-americano: um processo de luta das minorias. Revista Eletrônica Direito e Política, Programa de Pós-Graduação Stricto Sensu em Ciência Jurídica da UNIVALI, Itajaí, v.11, n.3, $3^{\circ}$ quadrimestre de 2016. Disponível em: www.univali.br/direitoepolitica - ISSN 1980-7791.

Esses povos tiveram destaque no desenvolvimento do novo constitucionalismo latino-americano, por meio de suas reivindicações para garantia de direitos e de respeito a sua identidade étnica, o que influenciou para a ampliação da participação política das minorias desses países. Por meio dessas reivindicações, o poder constituinte originário foi tirado do seu estado de latência e, invocando o conceito do povo como seu titular, rompeu com a ordem jurídica anterior, instaurando uma nova ordem constitucional que englobasse as exigências sociais surgidas.

Para Gargarella, as novas Constituições criadas visavam reparar pelo menos 3 falhas das anteriores: a desatenção com os direitos dos "negligenciados entre os negligenciados" (tipicamente, comunidades indígenas); o persistente desdém com os direitos humanos; e a incapacidade de garantir e tornar efetivo os direitos políticos, encorajando uma "cidadania ativa"25.

Visando demonstrar a aplicação prática do que se defende no novo constitucionalismo, trazemos à baila o art. 231 da CRFB/1988 ${ }^{26}$, que reconhece e positiva direitos à população indígena, a exemplo da inalienabilidade absoluta das terras que ocupam. É um reconhecimento do conteúdo político, cultural e jurídico dessas áreas. O dispositivo erige tais direitos fundamentais à tutela do Estado, que possui a função constitucional de proteger o exercício dos direitos dessa população, a saber:

Também podemos citar como exemplo de tutela jurisdicional desses direitos o famoso paradigma "Raposa do Sol", Petição no 3388, julgado pelo Supremo Tribunal Federal, que declarou constitucional a demarcação contínua da Terra

25 GARGARELLA, Roberto. Lo "viejo" del "Nuevo" constitucionalismo latino-americano. Disponível em < https://www.law.yale.edu/system/files/documents/pdf/SELA15_Gargarella_CV_Sp.pdf>. Acesso em 04.out.2016.

26 Art. 231. São reconhecidos aos índios sua organização social, costumes, línguas, crenças e tradições, e os direitos originários sobre as terras que tradicionalmente ocupam, competindo à União demarcá-las, proteger e fazer respeitar todos os seus bens [...].

$\S 20$ As terras tradicionalmente ocupadas pelos índios destinam-se a sua posse permanente, cabendo-Ihes o usufruto exclusivo das riquezas do solo, dos rios e dos lagos nelas existentes.

$\S 40$ As terras de que trata este artigo são inalienáveis e indisponíveis, e os direitos sobre elas, imprescritíveis (grifos nosso). 
ASSIS, Fábio José Silva de; VIEIRA, José Ribas. Do neoconstitucionalismo ao novo constitucionalismo latino-americano: um processo de luta das minorias. Revista Eletrônica Direito e Política, Programa de Pós-Graduação Stricto Sensu em Ciência Jurídica da UNIVALI, Itajaí, v.11, n.3, $3^{\circ}$ quadrimestre de 2016. Disponível em: www.univali.br/direitoepolitica - ISSN 1980-7791.

Indígena Raposa Serra do Sol. Muito embora o caminho ainda seja longo ao pleno exercício dos direitos dessas minorias étnicas, o ponto de partida já existe. A título de exemplificação, trazemos trecho do voto do Ministro Carlos Ayres Britto, relator do julgamento:

Exatamente porque dessa espécie de perdurável relação orgânica entre cada etnia indígena e o seu ainda rústico habitat é que se pode falar de direitos originários. Como também se pode falar de uma cultura tão diferenciada quando geradora de todo um perfil coletivo. Tudo a ser documentado em criteriosos laudos antropológicos, pois a sociedade "pluralista" de que trata o preâmbulo da nossa Constituição é do tipo social genérico, e, por isso mesmo, copiosa o bastante para alcançar as próprias diferenças entre os índios de uma etnia e de outra 27.

O Estado Plurinacional permitiu, portanto, a uniformização nacional, incluindo na Constituição inúmeros direitos dedicados à resolução de questões étnicas, antes ignorados por completo. Esse novo constitucionalismo permitiu, portanto, a inclusão dos povos indígenas como sujeitos políticos detentores de uma identidade estatal plurinacional e intercultural, características essa decorrentes de um modelo jurídico plural. Com isso, as Constituições Latino Americanas descentralizaram a produção de juridicidade do Estado, entregando-a para o povo, que após períodos de regimes autoritários, passou a pormenorizar seus direitos, a fim de evitar um novo regime opressor.

Roberto Viciano Pastor e Rubén Martínez Dalmau, na tentativa de sistematizar as características do novo constitucionalismo latino-americano, nos trazem algumas de suas principais características ${ }^{28}$. A primeira seria o surgimento de processos constituintes democráticos.

O novo constitucionalismo se diferencia do constitucionalismo anterior, no campo da legitimidade, pela natureza das suas Assembléias Constituintes. Isso porque

27 STF - Pet: 3388 RR, Relator: Carlos Britto, Data de Julgamento: 03/04/2009, Data de Publicação: DJe-071 DIVULG 16/04/2009 PUBLIC 17/04/2009.

28 MARTINEZ DALMAU, Rubén; VICIANO PASTOR, Roberto. ¿Se pude hablar de un nuevo constitucionalismo latinoamericano como corriente doctrinal sistematizada? Trabalho apresentado no Congresso Mundial de Direito constitucional, 2010. Disponível em: <http://www.juridicas.unam.mx/wccl/ponencias/13/245.pdf>. Acesso em: 10.jan.2015. 
ASSIS, Fábio José Silva de; VIEIRA, José Ribas. Do neoconstitucionalismo ao novo constitucionalismo latino-americano: um processo de luta das minorias. Revista Eletrônica Direito e Política, Programa de Pós-Graduação Stricto Sensu em Ciência Jurídica da UNIVALI, Itajaí, v.11, n.3, $3^{\circ}$ quadrimestre de 2016. Disponível em: www.univali.br/direitoepolitica - ISSN 1980-7791.

desde as primeiras constituições, responsáveis por fundar os Estados latino americanos, que esses Estados não tinham processos constituintes plenamente democráticos, mas sim processos constituintes representativos das elites.

Em seguida, surgiram novas constituições que se fundamentaram no "nominalismo constitucional", caracterizado pela falta de uma presença efetiva da constituição no ordenamento jurídico e na sociedade. Essas constituições do "velho constitucionalismo" cumpriam apenas os objetivos que haviam sido determinados pelas elites: a organização do poder do Estado e a manutenção, em alguns casos, dos elementos básicos de um sistema democrático formal.

César Garavito e Diana Franco defendem que esses processos constituintes democráticos teriam favorecido o surgimento de um ativismo dialógico, de forma que os tribunais dialógicos promovem a democracia, ao invés de corroê-la, ao exercerem um controle horizontal da responsabilidade de outros ramos do governo e ajudarem a romper bloqueios institucionais que contribuíam para violações massivas nos direitos econômicos, sociais e culturais. Além disso, fomentam, ao invés de inibir, a participação democrática e a deliberação coletiva, criando meios de diálogos dirigidos a solução de problemas ${ }^{29}$.

Em segundo lugar, Roberto Viciano Pastor e Rubén Martínez Dalmau trazem como característica comum do novo constitucionalismo latino-americano a presença de alguns elementos formais, como o conteúdo inovador (originalidade), sua amplitude, a capacidade de conjugar elementos tecnicamente complexos com uma linguagem acessível e o fato de se apostar pela ativação do poder constituinte do povo antes de qualquer alteração constitucional (rigidez).

Por fim, os autores nos indicam as características materiais desse novo constitucionalismo. Todas elas seriam importantes para a dinâmica constituinte: de um lado propõem a ativação direta do poder constituinte para o avanço das

${ }^{29}$ GARAVITO, César Rodríguez; FRANCO, Diana Rodríguez. Juicio a la exclusión: El impacto de los tribunales sobre los derechos sociales en el Sur Global. Franco.- $1^{\text {a }}$ ed.- Buenos Aires: Siglo Veintiuno Editores, 2015, p. 234. 
ASSIS, Fábio José Silva de; VIEIRA, José Ribas. Do neoconstitucionalismo ao novo constitucionalismo latino-americano: um processo de luta das minorias. Revista Eletrônica Direito e Política, Programa de Pós-Graduação Stricto Sensu em Ciência Jurídica da UNIVALI, Itajaí, v.11, n.3, $3^{\circ}$ quadrimestre de 2016. Disponível em: www.univali.br/direitoepolitica - ISSN 1980-7791.

sociedades e, de outro, a necessidade de romper com sistemas anteriores. São elas: (a) o compromisso constitucional de promover a participação da sociedade de forma direta; (b) a criação de novas cartas de direitos nas novas constituições, sem criar direitos de forma genérica, mas sim de forma individualizada e coletiva, identificando os setores historicamente marginalizados, como indígenas, mulheres, crianças, dentre outros; (c) a normatividade constitucional, que coloca a Constituição em um patamar superior frente ao restante do ordenamento jurídico; (d) e a necessidade de superar as desigualdades econômicas e sociais e de criar constitucionalmente um novo papel do Estado na economia.

Com isso, no novo constitucionalismo latino-americano a soberania popular reconquista seu lugar na teoria constitucional, passando o poder constituinte originário a ser exercido de acordo com a efetiva manifestação de vontade do povo, e não mais por uma imprecisa representação. Por esse motivo, essas Constituições costumam trazer em seu texto uma maior simplicidade linguística e uma gama de normas que busquem a integração de grupos marginalizados historicamente. Nesse sentido:

[...] a principal aposta do novo constitucionalismo latinoamericano está na busca por instrumentos que recomponham a perdida (ou nunca alcançada) relação entre soberania e governo. O que a Constituição Colombiana de 1991 chama de "Formas de participação democrática", no Equador de 1998 se chama governo participativo; na Venezuela e na Bolívia recebe o nome de democracia participativa; e no Equador de 2008, "A participação na democracia." O denominador comum é o mesmo: estabelecer mecanismos de legitimidade e controle sobre o poder constituído através, em muitos casos, de novas formas de participação obrigatória. Este fator se conecta diretamente com a originalidade constitucional a que se fez referência, necessária no exercício da inovação que tem plantado as novas Constituições, e que de forma definitiva constitucionaliza vários dos instrumentos de participação e anseios democráticos do continente ${ }^{30}$.

${ }^{30}$ GARAVITO, César Rodríguez; FRANCO, Diana Rodríguez. Juicio a la exclusión: El impacto de los tribunales sobre los derechos sociales en el Sur Global. Franco.- $1^{\text {a }}$ ed.- Buenos Aires: Siglo Veintiuno Editores, 2015, p. 234. 
ASSIS, Fábio José Silva de; VIEIRA, José Ribas. Do neoconstitucionalismo ao novo constitucionalismo latino-americano: um processo de luta das minorias. Revista Eletrônica Direito e Política, Programa de Pós-Graduação Stricto Sensu em Ciência Jurídica da UNIVALI, Itajaí, v.11, n.3, $3^{\circ}$ quadrimestre de 2016. Disponível em: www.univali.br/direitoepolitica - ISSN 1980-7791.

Conseqüente característica desse novo modelo é a criação de mecanismos de democracia participativa e de extensão dos direitos fundamentais. Roberto Viciano Pastor e Rubén Martínez Dalmau trazem o processo constituinte da Venezuela como o exemplo mais revelador do novo constitucionalismo latinoamericano:

A Constituição da República Bolivariana da Venezuela, votada majoritariamente pelo povo venezuelano em 15 de Dezembro de 1999, foi principalmente, uma Constituição necessária. Desde o primeiro grande protesto, o chamado Caracazo em 1989, quando milhares de pessoas saíram às ruas para expressar sua aversão ao sistema de corrupto, elitista e marginador, até que a vitória de Hugo Chávez em dezembro de 1998, passando pelos golpes de Estado de 1992 que, indiretamente, acabariam com o governo de Carlos Andrés Perez, 30, a sociedade venezuelana terminou por impor a sua vontade de aprofundar a democracia através da participação, das políticas de igualdade, do progresso nos direitos e da melhora das condições de vida dos venezuelanos através de uma cobertura social adequada, a criação de um tecido produtivo e uma melhor distribuição das receitas petrolíferas. ${ }^{31}$.

Outro exemplo desse novo constitucionalismo Latino-Americano é citado por Eric Fernandes e Siddharta Ferreira, que demonstram a influência dessa plurinacionalidade nos artigos da Constituição Colombiana:

Especificamente no caso colombiano, podemos encontrar algumas características desse novo constitucionalismo presentes em sua Constituição. Em primeiro lugar, há a definição da Colômbia como um estado democrático e social de direito, que constitui uma republica participativa (art.10). A Constituição colombiana de 1991, em seu artigo 4011, garante o direito de todo cidadão de participar para conformar ou fiscalizar o poder político. Para tanto, o art. 41 considera obrigatório 0 estudo da Constituição nos estabelecimentos de ensino de caráter público ou de caráter privado. No mesmo sentido, o art. 103, prevê uma série de mecanismos de participação popular, tais como plebiscito, referendo, consulta popular, iniciativa legislativa, revocatória

31 MARTINEZ DALMAU, Rubén; VICIANO PASTOR. Roberto. Los Procesos Constituyentes Latinoamericanos $y$ el nuevo paradigma constitucional. Revista del Instituto de Ciencias Jurídicas de Puebla A.C., México, 2010. Disponível em: <http://www.redalyc.org/articulo.oa?id=293222977001>. Acesso em 10.jan.2016. 
ASSIS, Fábio José Silva de; VIEIRA, José Ribas. Do neoconstitucionalismo ao novo constitucionalismo latino-americano: um processo de luta das minorias. Revista Eletrônica Direito e Política, Programa de Pós-Graduação Stricto Sensu em Ciência Jurídica da UNIVALI, Itajaí, v.11, n.3, $3^{\circ}$ quadrimestre de 2016. Disponível em: www.univali.br/direitoepolitica - ISSN 1980-7791.

de mandato e "cabildos abiertos" (CALLE, 2008, p. 131 e ss.). Chega-se, por isso, por exemplo, a prever a necessidade de um referendo para revogar leis de iniciativa popular. Vale enfatizar a possibilidade de iniciativa popular para aprovar uma lei ou reforma à Constituição (art.155), bem como a de revogação do mandato - recall- como uma forma de controle do poder político $\left(\right.$ art.40) ${ }^{32}$.

Exemplo interessante a ser abordado no que tange ao constitucionalismo latinoamericano, pelas recentíssimas implicações ocorridas no país, é o da Constituição Boliviana. O projeto de Constituição boliviana, entregue pela Assembléia Nacional Constituinte em 14 de dezembro de 2007 e aprovado pelo povo em janeiro de 2009, incorporou reivindicações que vinham desde os anos 90 e exigiam a troca da Constituição por uma que lutasse pela integração social, pelo bem estar do povo, pela ampliação e aplicação dos direitos e por um governo que respondesse as expectativas dos cidadãos ${ }^{33}$.

Com a convocação da Assembléia Nacional Constituinte, se instalou o governo do Presidente Evo Morales. No entanto, a participação do poder constituído na convocatória da Assembléia, ao invés da ativação direta do poder constituinte por meio de referendo, foi o pior erro do processo constituinte boliviano, porque teve um impacto não só no reconhecimento por parte de alguns setores da população do caráter originário da Assembléia Constituinte, mas, pior, na autoconcepção originária da própria Assembléia, o que a impedia de tomar decisões chave quando as condições sociais e políticas requeriam.

Com isso, o projeto de Constituição se manteve durante boa parte de 2008 sem futuro certo. Posteriormente, em outubro de 2010, momento que a Assembléia Constituinte levava mais de 10 meses em recesso, o governo fechou as negociações com a oposição no Congresso Nacional, promovendo modificações

32 FERNANDES, Eric Baracho Dore; FERREIRA, Siddharta Legale. o controle jurisdicional das omissões legislativas no novo constitucionalismo latino-americano: um estudo comparado entre Brasil e Colômbia. Disponível em < http://www.publicadireito.com.br/artigos/?cod=f9fd2624beefbc78>. Acesso em: 11.jan.2015.

33 MARTINEZ DALMAU, Rubén; VICIANO PASTOR. Roberto. Los Procesos Constituyentes Latinoamericanos $y$ el nuevo paradigma constitucional. Revista del Instituto de Ciencias Jurídicas de Puebla A.C., México, 2010. Disponível em: <http://www.redalyc.org/articulo.oa?id=293222977001>. Acesso em 10.jan.2016. 
ASSIS, Fábio José Silva de; VIEIRA, José Ribas. Do neoconstitucionalismo ao novo constitucionalismo latino-americano: um processo de luta das minorias. Revista Eletrônica Direito e Política, Programa de Pós-Graduação Stricto Sensu em Ciência Jurídica da UNIVALI, Itajaí, v.11, n.3, $3^{\circ}$ quadrimestre de 2016. Disponível em: www.univali.br/direitoepolitica - ISSN 1980-7791.

no projeto da Constituição, em muitas delas retrocedendo frente ao texto original criado pela Assembléia Constituinte. Ainda assim, a nova Constituição trouxe um caráter plurinacional de Estado, com a convivência de elementos liberais e indígenas, a aposta pela regeneração democrática, o valor dos direitos sociais, o papel do Estado na economia, dentre outras modificações.

Além dos já citados acima, também podemos trazer exemplos desse novo constitucionalismo nos textos constitucionais de países vizinhos. A Constituição do Equador, diz no seu art. $1^{\circ}$ :

Art. 1.- El Ecuador es un estado social de derecho, soberano,
unitario, independiente, democrático, pluricultural y
multiétnico. Su gobierno es Republicano, presidencial,
electivo, representativo, responsable, alternativo,
participativo y de administración descentralizada. La
soberanía radica en el pueblo, cuya voluntad es la base de la
autoridad, que ejerce a través de los órganos del poder
público y de los medios democráticos previstos en esta
Constitución. El Estado respeta y estimula el desarrollo de
todas las lenguas de los ecuatorianos. El castellano es el
idioma oficial. El quichua, el shuar y los demás idiomas
ancestrales son de uso oficial para los pueblos indígenas, en
los términos que fija la ley. La bandera, el escudo y el himno
establecidos por la ley, son los símbolos de la pátria.

O artigo acima, ao trazer a definição constitucional do Estado Equatoriano, agrega princípios e conceitos que vem das mais diversas tradições, ideologias e visões. Caracteriza o Estado como "pluricultural, e multiétnico" e explicita que a soberania irradia do povo, de forma a incluir todas as culturas e etnias no próprio conceito do Estado. Como se não bastasse os itens anteriores, ainda no art. $1^{0}$ a Constituição traz o uso oficial das línguas ancestrais dos povos indígenas, como meio de respeitar esses povos e integrar essa parcela até então marginalizada pelas cartas constitucionais anteriores.

Essa mesma preocupação com a inclusão e respeito com o multiculturalismo e o respeito a língua dos povos indígenas é demonstrada no art. $5^{\circ}$ da Constituição Boliviana, que nos diz que:

Artículo 5. I. Son idiomas oficiales del Estado el castellano y todos los idiomas de las naciones y pueblos indígenas 
ASSIS, Fábio José Silva de; VIEIRA, José Ribas. Do neoconstitucionalismo ao novo constitucionalismo latino-americano: um processo de luta das minorias. Revista Eletrônica Direito e Política, Programa de Pós-Graduação Stricto Sensu em Ciência Jurídica da UNIVALI, Itajaí, v.11, n.3, $3^{\circ}$ quadrimestre de 2016. Disponível em: www.univali.br/direitoepolitica - ISSN 1980-7791.

originarios campesinos, que son el aymara, araona, baure, bésiro, canichana, cavineño, cayubaba, chácobo, chimán, ese ejja, guaraní, guarasuawe, guarayu, itonama, leco, machajuyai-kallawaya, machineri, maropa, mojeñotrinitario, mojeño-ignaciano, moré, mosetén, movima, pacawara, puquina, quechua, sirionó, tacana, tapiete, toromona, uruchipaya, weenhayek, yaminawa, yuki, yuracaré y zamuco.

Ainda utilizando a Constituição Boliviana a título exemplificativo, em seu art. $8^{\circ}$ é consagrado como princípio ético-moral o "Sumak Kamaña", que significa "viver bem" na língua nativa do povo indígena, demonstrando a preocupação em representar um texto constitucional que agregue todos os povos.

Art. $8^{\circ}$ El Estado asume y promueve como principios éticomorales de la sociedad plural: ama qhilla, ama llulla, ama suwa (no seas flojo, no seas mentiroso ni seas ladrón), suma kamaña (vivir bien), ñandereko (vida armoniosa), teko kavi (vida buena), ivimaraei (tierra sin mal) y qhapaj ñan (camino o vida noble)

A presença das características citadas acima do novo constitucionalismo latino americano estão presentes de forma tão marcante na constituição boliviana de 2009, que dos seus 411 artigos, 80 tratam de direitos indígenas, trazendo direitos como: cotas para parlamentares oriundos de povos indígenas; equivalência entre a justiça indígena e a comum; garantia de recursos hídricos e florestais pelas comunidades indígenas; dentre outros.

Na Constituição Venezuelana, a preocupação em garantir a participação popular no próprio texto constitucional é tão marcante que o elemento popular é garantido nas reformas constitucionais, ainda que em detrimento de instituições representativas e elitistas. Aos cidadãos é garantido um relevante papel no processo de revisão e criação constitucional. Com isso, é garantida a participação popular nos processos de reforma da constituição, inclusive em seu aspecto formal, permitindo que os cidadãos convoquem uma Assembléia Nacional Constituinte para a criação de um novo ordenamento jurídico e uma nova Constituição, caso entendam necessário.

Artículo 347. El pueblo de Venezuela es el depositario del poder constituyente originario. En ejercicio de dicho poder, 
ASSIS, Fábio José Silva de; VIEIRA, José Ribas. Do neoconstitucionalismo ao novo constitucionalismo latino-americano: um processo de luta das minorias. Revista Eletrônica Direito e Política, Programa de Pós-Graduação Stricto Sensu em Ciência Jurídica da UNIVALI, Itajaí, v.11, n.3, $3^{\circ}$ quadrimestre de 2016. Disponível em: www.univali.br/direitoepolitica - ISSN 1980-7791.

puede convocar una Asamblea Nacional Constituyente con el objeto de transformar el Estado, crear un nuevo ordenamiento jurídico y redactar una nueva Constitución.

Os artigos citados acima demonstram que as Constituições desse novo movimento constitucional não se limitaram a reconhecer direitos dos povos originários, mas a internalizar costumes e tradições dos povos indígenas, que eram originariamente excluídos do processo de produção e aplicação do direito.

No entanto, podemos questionar se a criação de tantas ferramentas para o exercício da democracia direta também não seriam prejudiciais para o país. No caso da Bolívia, o povo, por referendo, vem permitindo a manutenção no poder de seu Presidente, Evo Morales, pelo terceiro mandato consecutivo. Dar poder a um povo ambientado com a ditadura poderia representar a perpetuação de um modelo ditatorial, já que, independentemente do modelo de política adotada pelo atual presidente, é o próprio povo que vem impedindo a rotatividade no poder, por meio de emendas constitucionais aprovadas por referendo.

Claramente, por meio do novo constitucionalismo latino-americano, foram usadas ferramentas de democracia participativa contra a própria democracia, gerando um quadro de instabilidade política prejudicial a toda população.

No contexto brasileiro, Cesar Baldi afirma que é adotado um constitucionalismo que, sistematicamente, tem voltado as costas para a realidade latino-americana, concentrando suas atenções no desenvolvimento de teorias eurocentradas. Com isso, o autor acredita que ainda vai demorar para ser assimilado o processo de descolonização, plurinacionalidade e interculturalidade, que os movimentos constituintes da Bolívia e do Equador, em grande parte protagonizados por indígenas, inauguram no âmbito continental ${ }^{34}$.

Ainda assim, podemos considerar que o novo constitucionalismo latinoamericano tem obtido sucesso nos países em que foi implementado, buscando

34 BALDI, Cesar Augusto. Direito Constitucional e Constitucionalismo interno. Interculturalidade, direitos humanos e pluralismo jurídico. 2010. Disponível em <http://ccr6.pgr.mpf.gov.br/documentos-epublicacoes/docs_artigos/interculturalidade-direitoshumanos-e-pluralismojuridico/view>. Acesso em 03.out.2016. 
ASSIS, Fábio José Silva de; VIEIRA, José Ribas. Do neoconstitucionalismo ao novo constitucionalismo latino-americano: um processo de luta das minorias. Revista Eletrônica Direito e Política, Programa de Pós-Graduação Stricto Sensu em Ciência Jurídica da UNIVALI, Itajaí, v.11, n.3, $3^{\circ}$ quadrimestre de 2016. Disponível em: www.univali.br/direitoepolitica - ISSN 1980-7791.

positivar direitos pluralistas que englobem a todos os povos e suas culturas, inibindo a discriminação e colocando seus cidadãos em um estado de igualdade formal.

\section{CONSIDERAÇÕES FINAIS}

O neoconstitucionalismo trouxe uma série de avanços sociais, que na América Latina não se mostraram suficientes, surgindo diversos movimentos populares que clamavam por reconhecimento de direitos e participação política, motivo pelo qual surgiu o novo constitucionalismo latino-americano, que, em um Estado Plurinacional, reconheceu e garantiu direitos dessas parcelas da sociedade.

No entanto, a implementação de direitos na teoria é o primeiro passo, mas ainda há muitos outros passos a serem dados para que essa teoria surta efeito na realidade prática. Criar direitos não é o mesmo que efetivá-los. Por isso, ainda é importante que esses Estados Latino-Americanos criem meios de que essas normas plurais sejam respeitadas e levadas adiante.

Muitos desses países ainda possuem traços das suas Constituições anteriores, com características autoritárias, mas de forma gradual têm conseguido grandes conquistas sociais. Diante disso, é inquestionável que houve uma grande evolução nos direitos das minorias nesses países, principalmente quanto aos direitos indígenas, trazendo uma nova concepção de Estado e de nação.

\section{REFERÊNCIAS DAS FONTES CITADAS}

BALDI, César Augusto. Novo constitucionalismo latino-americano. Revista Estado de Direito, Porto Alegre, 2011. Disponível em <http://files.campus.edublogs.org/blogs.udla.edu.ec/dist/0/59/files/2011/11/nov oconstitucionalismolatinoamericano-portugues-1z5jvul.pdf $>$. Acesso em: 15.jan.2015. 
ASSIS, Fábio José Silva de; VIEIRA, José Ribas. Do neoconstitucionalismo ao novo constitucionalismo latino-americano: um processo de luta das minorias. Revista Eletrônica Direito e Política, Programa de Pós-Graduação Stricto Sensu em Ciência Jurídica da UNIVALI, Itajaí, v.11, n.3, $3^{\circ}$ quadrimestre de 2016. Disponível em: www.univali.br/direitoepolitica - ISSN 1980-7791.

BALDI, César Augusto. Direito Constitucional e Constitucionalismo interno. Interculturalidade, direitos humanos e pluralismo jurídico. 2010. Disponível em <http://ccr6.pgr.mpf.gov.br/documentosepublicacoes/docs_artigos/interculturalidade-direitos-humanos-epluralismojuridico/view>. Acesso em 03.out.2016.

BARROSO, Luis Roberto. Neoconstitucionalismo e constitucionalização do Direito: O triunfo tardio do Direito Constitucional no Brasil. Revista de Direito Administrativo da FGV, Rio de Janeiro, 2005. Disponível em: <http://bibliotecadigital.fgv.br/ojs/index.php/rda/article/view/43618/44695>. Acesso em: 05.set.2015.

BARROSO, Luís Roberto. Interpretação e Aplicação da Constituição. 6 ed. São Paulo: Saraiva, 2008.

DUARTE, Écio Oto Ramos; POZZOLO, Susanna. Neoconstitucionalismo e positivismo jurídico: as faces da teoria do Direito em tempos de interpretação moral da Constituição. São Paulo: Landy, 2006.

FERREIRA FILHO, Manoel Gonçalves. Estado de direito e constituição. São Paulo: Saraiva, 1988.

FERNANDES, Eric Baracho Dore; FERREIRA, Siddharta Legale. O controle jurisdicional das omissões legislativas no novo constitucionalismo latino-americano: um estudo comparado entre Brasil e Colômbia. Disponível em

http://www.publicadireito.com.br/artigos/?cod=f9fd2624beefbc78>. Acesso em: 11.jan.2015.

FLORES, Joaquín Herrera El processo cultural: materiales para La creatividad humana. Sevilla, Aconchagua Libros, 2005.

FLORES, Joaquin Herrera. Teoria crítica dos direitos humanos. Rio de Janeiro, Lumen Juris, 2009.

GARAVITO, César Rodríguez; FRANCO, Diana Rodríguez. Juicio a la exclusión: El impacto de los tribunales sobre los derechos sociales en el Sur Global. Franco.- $1^{\text {a }}$ ed.- Buenos Aires: Siglo Veintiuno Editores, 2015.

GARGARELLA, Roberto. Lo "viejo" del "Nuevo" constitucionalismo latinoamericano. Disponível em < https://www.law.yale.edu/system/files/documents/pdf/SELA15_Gargarella_CV_S p.pdf>. Acesso em 04.out.2016.

LOPERO, Gloria. La aplicación del derecho es los sistemas jurídicos constitucionalizados. Revista Cuadernos de Investigación, Medellin. Disponível em <http://publicaciones.eafit.edu.co/index.php/cuadernosinvestigacion/article/view/1325/1196>. Acesso em 20.out.2015. 
ASSIS, Fábio José Silva de; VIEIRA, José Ribas. Do neoconstitucionalismo ao novo constitucionalismo latino-americano: um processo de luta das minorias. Revista Eletrônica Direito e Política, Programa de Pós-Graduação Stricto Sensu em Ciência Jurídica da UNIVALI, Itajaí, v.11, n.3, $3^{\circ}$ quadrimestre de 2016. Disponível em: www.univali.br/direitoepolitica - ISSN 1980-7791.

MACHADO, Lucas ; WOLKMER, Antonio Carlos. Pluralismo jurídico no horizonte do pensamento crítico de libertação Latino-Americana. In: Beatriz Rajland ; Mauro Benente. (Org.). El derecho y el Estado : procesos políticos y constituyentes en nuestra América. Buenos Aires: CLACSO, 2016.

MAGALHÃES, José Luiz Quadros de. Estado plurinacional e direito internacional. Curitiba: Juruá, 2012.

MAgAlHÃES, José Luiz Quadros de. O Estado Plurinacional na América Latina. Conteúdo Jurídico, Brasília-DF: 2009. Disponível em: <http://www.conteudojuridico.com.br/?colunas\&colunista $=50 \& v e r=257>$.

Acesso em: 19 jan. 2015.

MARTINEZ DALMAU, Rubén; VICIANO PASTOR, Roberto. ¿Se pude hablar de un nuevo constitucionalismo latinoamericano como corriente doctrinal sistematizada? Trabalho apresentado no Congresso Mundial de Direito constitucional, $2010 . \quad$ Disponível em: <http://www.juridicas.unam.mx/wccl/ponencias/13/245.pdf>. Acesso em: 10.jan.2015.

MARTINEZ DALMAU, Rubén; VICIANO PASTOR. Roberto. Los Procesos Constituyentes Latinoamericanos y el nuevo paradigma constitucional. Revista del Instituto de Ciencias Jurídicas de Puebla A.C., México, 2010. Disponível em: <http://www.redalyc.org/articulo.oa?id=293222977001>. Acesso em 10.jan.2016.

SANTOS, Boaventura de Sousa. La reinvención del Estado y el Estado plurinacional, OSAL, Buenos Aires, 2007. Disponível em <http://bibliotecavirtual.clacso.org.ar/ar/libros/osal/osal22/D22SousaSantos.pdf >. Acesso em: 21.dez.14.

SANTOS, Boaventura de Sousa. Reconhecer para libertar: os caminhos do cosmopolitismo cultural. Rio de Janeiro: Civilização Brasileira, 2003.

SANTOS, Boaventura de Sousa. Renovar a teoria crítica e reinventar a emancipação social. São Paulo: Boitempo, 2007.

STRECK, Lênio Luiz. Hermenêutica, Neoconstitucionalismo e "o problema da discricionariedade dos juízes". Revista Eletrônica do Curso de Direito da OPET, Curitiba, 2009. Disponível em <http://www.animaopet.com.br/primeira_edicao/artigo_Lenio_Luiz_Streck_hermeneutica.pdf $>$.

Acesso em 11.jan.2015.

VALE, Andre Rufino do. Aspectos do Neoconstitucionalismo. Revista Brasileira de Direito Constitucional, São Paulo, 2007. Disponível em <http://www.esdc.com.br/RBDC/RBDC-09/RBDC-09-067-

Andre_Rufino_do_Vale.pdf>. Acesso em: 11.jan.2015

WOLKMER, Antonio Carlos. Pluralismo e Constitucionalismo na Tradição Jurídico Brasileira e Latino-Americana. Conferência: Pluralismo e 
ASSIS, Fábio José Silva de; VIEIRA, José Ribas. Do neoconstitucionalismo ao novo constitucionalismo latino-americano: um processo de luta das minorias. Revista Eletrônica Direito e Política, Programa de Pós-Graduação Stricto Sensu em Ciência Jurídica da UNIVALI, Itajaí, v.11, n.3, 30 quadrimestre de 2016. Disponível em: www.univali.br/direitoepolitica - ISSN 1980-7791.

constitucionalismo no Brasil, proferida no II Congresso de Estudos Jurídicos do Centro Acadêmico Cromwell de Carvalho e Escola Superior de Advocacia do Piauí, realizado em 2011, em Teresina - Piauí - Brasil.

Submetido em: maio/2016

Aprovado em: setembro/2016 